\title{
NO and OH Spectroscopic Vibrational Temperature Measurements in a Postshock Relaxation Region
}

\author{
M. Sharma,,$*$ J. M. Austin,, \pm and N. G. Glumac \pm \\ University of Illinois at Urbana-Champaign, Urbana, Illinois 61801 \\ and \\ L. Massa $\underline{\S}$ \\ University of Texas at Arlington, Arlington, Texas 76019
}

\begin{abstract}
DOI: $10.2514 / 1 . J 050047$
In this paper, spatial temperature profiles are examined in the nonequilibrium relaxation region behind a stationary shock wave in a hypervelocity air Mach 7.42 freestream. The normal shock wave is established through a Mach reflection from an opposing wedge arrangement in an expansion tube facility. Schlieren images confirm that the shock configuration is steady and the location is repeatable. Emission spectroscopy is used to identify dissociated species and to make vibrational temperature measurements using both the nitric oxide and the hydroxyl radical $A-X$ band sequences. Temperature measurements are presented at selected locations behind the normal shock. LIFBASE is used as the simulation spectrum software for $\mathrm{OH}$ temperature-fitting; however, the need to access higher vibrational and rotational levels for $\mathrm{NO}$ leads to the use of an in-house developed algorithm. For NO, results demonstrate the contribution of higher vibrational and rotational levels to the spectra at the conditions of this study. Very good agreement is achieved between the experimentally measured NO vibrational temperatures and calculations performed using an existing state-resolved, three-dimensional forced-harmonic oscillator thermochemical model. The measured NO vibrational temperatures are significantly higher than the $\mathrm{OH}$ temperatures.
\end{abstract}

\section{Introduction}

A T HYPERSONIC conditions encountered during atmospheric planetary entry, molecular real gas processes become significant. Thermal transitions and chemical reactions are known to affect flight aerodynamics, for example increased energy absorption by chemical reactions leads to a decreased shock standoff distance for a given test configuration [1]. Behind a strong shock, high temperatures and large radiative heating rates occur. The extent and profile of the postshock relaxation region must be predicted to infer aerothermodynamic loads on the vehicle body. The complexity of a thermochemically active, hypersonic flow tests the current limits of computational modeling [2]. Experimental data, particularly obtained using nonintrusive techniques, are therefore valuable, but conditions are typically challenging for measurement diagnostics.

The goal of this study is to investigate the nonequilibrium relaxation region behind a normal shock using spectroscopic radiation measurements. By doing so, we aim to demonstrate the applicability of emission spectroscopy as a diagnostic for hypervelocity flows. The normal shock is created via a Mach reflection (MR) using an opposing wedge arrangement. The choice of a normal shock eliminates flowfield complexities associated with a curved bow shock, such as mixed subsonic-supersonic regions, entropy gradients due to flow curvature, and three-dimensionality. Nitric oxide $A-X$ (also referred to as the gamma, or $\gamma$ band) and hydroxyl radical $A-X$ band transitions are used to measure postshock

Received 6 July 2009; revision received 29 January 2010; accepted for publication 31 January 2010. Copyright $\odot 2010$ by University of Illinois. Published by the American Institute of Aeronautics and Astronautics, Inc., with permission. Copies of this paper may be made for personal or internal use, on condition that the copier pay the $\$ 10.00$ per-copy fee to the Copyright Clearance Center, Inc., 222 Rosewood Drive, Danvers, MA 01923; include the code 0001-1452/10 and \$10.00 in correspondence with the CCC.

${ }^{*}$ Graduate Student, Department of Aerospace Engineering. Member AIAA.

${ }^{\dagger}$ Assistant Professor, Department of Aerospace Engineering. Senior Member AIAA.

PProfessor, Department of Mechanical Science and Engineering. Member AIAA.

${ }^{\S}$ Assistant Professor, Department of Mechanical and Aerospace Engineering. Senior Member AIAA. vibrational temperature profiles in a high-enthalpy, nominal Mach 7.4 air flow.

$\mathrm{NO}$ and $\mathrm{OH}$ spectral data have previously been the focus of a series of sounding rocket flight experiments measuring ultraviolet emission behind a bow shock which were carried out in an effort to validate aerodynamic and radiative transfer models at reentry conditions [3]. Single scans at 89.7 to $76.4 \mathrm{~km}$ were dominated by nitric oxide $(A-\bar{X})$ gamma band emissions. In contrast, the summed spectra at $100 \mathrm{~km}$ was dominated by hydroxyl $(A-X)$ bands, primarily $(1,0)$ and $(0,0)$. Significant computational and theoretical analyses have been completed upon these data. Initially, the primary aim was to compare radiation model predictions with data based upon spectral emission obtained from four NO electronic bands [4-6]. With only $A-X$ band radiation being observed for the $\mathrm{OH}$ molecule, focus then shifted to developing $\mathrm{OH}$ specific radiation models for comparison with the experimental data. Numerical investigations have been completed based upon these models including work completed by Levin et al. [7-10], Gimelschein et al. [11], Kossi and Boyd [12], and Levin et al. [13]. In certain cases, significant differences were found between $\mathrm{OH}$ A-system vibrational temperature and those of the bulk flow. With outstanding issues arising from the flight experiments, one aim of this study is to provide additional temperature data behind hypersonic shock fronts with strong $\mathrm{OH} A-X$ emission at elevated temperatures.

In a partially dissociated and vibrationally excited freestream, Nerem et al. have measured relaxation times of dissociated air behind a normal shock for shock speeds between 4.9 to $6.8 \mathrm{~km} / \mathrm{s}$ by examining the radiative emission time-history [14]. Vibrational temperatures and relaxation times behind normal shock waves, with shocked temperatures between 1400-3200 K, were measured by Russo for CO test gas mixtures [15]. Time-resolved vibrational temperature measurements of $\mathrm{CO}$ were made using the emission band-reversal method and the line-reversal method for seeded sodium by assuming equilibrium between $\mathrm{CO}$ vibrational and sodium electronic temperatures. In the Mach range of 3.5-5.7, Moser and Hindelang measured nitric oxide vibrational relaxation times behind incident normal shock waves [16,17]. Moser and Hindelang employed infrared diode laser absorption spectroscopy tuned to specific ro-vibrational transitions for a NO-Ar gas mixture. At shock velocities of $6.2 \mathrm{~km} / \mathrm{s}$, Sharma and Gillespie conducted rotational and vibrational temperature measurements behind a normal shock [18], which sought to advance previous nonequilibrium relaxation 
region measurements by Allen et al. [19-21]. In each of these cases, nitrogen was the test gas. Sharma and Gillespie [18] completed their measurements using photomultiplier tube radiometers and the second positive system of $\mathrm{N}_{2}$. Using the Marseille free-piston shock tube and a shock velocity of $5.8 \mathrm{~km} / \mathrm{s}$, Labracherie et al. studied the nonequilibrium region downstream of a normal shock wave [22]. Labracherie et al. presented the temporal evolution of vibrational and rotational temperatures and did not specifically investigate spatial temperature gradients. Temperature measurements were made for a methane-nitrogen-argon mixture using the $\mathrm{CN} B-X$ electronic transition. Using the spontaneous emission of the $\Delta v=0$ band of $\mathrm{CN}$, Ramjuan et al. spatially measured the relaxation region behind a normal shock with a velocity of $5.6 \mathrm{~km} / \mathrm{s}$ [23]. Recently, Rond et al. used the $\mathrm{CN}$ violet system to show time-resolved postshock intensity profiles and to measure postshock vibrational temperatures using emission spectroscopy [24].

These previous studies demonstrate that emission spectroscopy is a viable technique for determining internal energy mode temperatures within a nonequilibrium flowfield. $\mathrm{CO}_{2}$ flowfields were the focus of many of the experimental studies that utilized emission spectroscopy as the diagnostic technique, and $\mathrm{CN}$ was the species of interest. In the current study, we examine air flows with $\mathrm{NO}$ and $\mathrm{OH}$ as the emitter species. Experimental results from Calspan University of Buffalo Research Center, for shock velocities between 3-4 km/s, used emission spectroscopy to identify the NO $A-X$ band as the dominant radiator behind strong shocks for $\mathrm{O}_{2}-\mathrm{N}_{2}$ gas mixture [25]. A follow-up experimental study used the region behind the shock wave to determine the squared transition moment value of the NO gamma band and to obtain time-dependent NO gamma radiative signals [26]. The calculation of internal energy mode temperatures using radiation signals from $\mathrm{NO}$ band systems via comparison with numerical spectra simulation has been successfully demonstrated on numerous occasions in air plasma experiments. In the NASA Ames $20 \mathrm{MW}$ arcjet wind tunnel, vibrational temperatures have been measured by using the emission spectra of the NO $\gamma(A-X)$ and $\delta$ $(C-X)$ bands $[27,28]$. In the same facility, rotational temperatures have also determined using the NO $\delta(0,4), \gamma(0,0), \gamma(0,1), \gamma(0,2)$, and $\gamma(0,3)$ bands [29]. Using strong $\gamma$ and weaker $\beta(B-X), \delta$, and $\epsilon$ $(D-X)$ band transitions, all internal energy mode temperatures were measured for plasma discharges in air [30].

In the previous shock wave studies, measurements have been made behind propagating waves. In the present experiments, we instead establish a stationary shock using an opposing double wedge model geometry. The flowfield is first visualized using the schlieren technique. Shock angles are measured, and since the free stream inflow conditions are known, the frozen postshock state is wellcharacterized.

The shock tube was almost exclusively the only type of impulse facility used in the previous experimental studies discussed above. In reflected-shock tunnels, chemical freezing within the nozzle and freestream nonequilibrium effects can alter the test gas [31-33]. An expansion tube is an alternate means of achieving high-enthalpy hypersonic conditions. Therefore, this work also serves as a test bed for demonstrating the applicability of emission spectroscopic techniques for temperature measurement within an expansion tube. Emission spectroscopy can provide useful data for facility characterization. At the TCM2 free-piston shock tunnel in France, emission spectra have been used to calculate useful test times and demonstrate test-time homogeneity for different operating conditions [34,35]. Test-time determination and species identification in the JX1 expansion tube facility using emission spectroscopy was performed by Ramjuan et al. [36]. Expansion tubes typically exhibit shorter test times than those exhibited in shock-tube and arcjet wind tunnel facilities, which reduces the emission signal strength. To the knowledge of the authors, this is the first study to conduct vibrational temperature measurements using optical emission spectroscopy in an expansion tube.

\section{Experimental Setup}

\section{A. Hypervelocity Expansion Tube Facility}

The hypervelocity expansion tube (HET) is a $9.14 \mathrm{~m}$ long facility consisting of three sections (driver, driven, and accelerator) all with $150 \mathrm{~mm}$ inner bore diameter, initially separated by primary and secondary diaphragms. The initial gas pressure and composition can be varied to achieve nominal Mach number operating conditions between 3.0 to 8.5 and stagnation enthalpies of 4.5 to $8.0 \mathrm{MJ} / \mathrm{kg}$. In the present study, an air test gas, helium driver, and accelerator gas run condition (labeled Air-5) with Mach number 7.42 is selected. Calculated test gas properties are shown in Table 1 .

The facility is initially evacuated, then each section filled to the desired initial pressure. Both dry (bottled) and moist (room) air were used as the test gas. The primary diaphragm burst pressure (driver pressure) is measured using a Setra 206 pressure gauge. Driven and accelerator initial fill pressures are monitored using MKS Piezo + A900-02 transducers. Vacuum pressures (below 2000 mtorr) in the accelerator section are measured using a MKS Baratron 626A transducer with 2 torr full scale, rated to $0.25 \%$ of the reading. This model was deliberately selected as the capacitance manometer pressure-measurement mechanism is invariant to the gas composition. Initial pressures in the accelerator section are typically on the order of 300 mtorr, and the influence of air-leakage into the acceleration section is mitigated by initially evacuating the section down to 200 mtorr, flushing with helium up to $12 \mathrm{kPa}$, and then performing the final evacuation down to the desired pressure. Within the facility, the acceleration section leak-rate was measured to be 0.3-0.4 $\mathrm{m}$ torr $/ \mathrm{min}$, and the subsequent partial pressure of air based upon these leak-rate measurements is low enough such that the effect is negligible based on perfect-gas dynamic calculations. Characterization of the out-gassing phenomena for these set of experiments, yielded a maximum 7 mtorr increase after the final accelerator evacuation. Pressure data were recorded using a National Instruments data acquistion system, consisting of a PXI-1031 chassis, a BNC-2100 eight-channel connector block, and a 14-bit PXI-6133 $3 \mathrm{MS} / \mathrm{s}$ simultaneous sampling multifunction data acquisition module. A full description of the facility, measurement capabilities, and facility operation can be found in Dufrene et al. [37]. Facilty operation has been previously characterized experimentally and numerically $[\underline{37}, \underline{38}]$.

In an expansion tube, imperfect secondary diaphragm rupture, shorter test times, and core flow reduction due to acceleration section viscous effects result in a challenging measurement environment. However, the advantages of minimized freestream dissociation and no nonequilibrium processes during a nozzle expansion, make the expansion tube an attractive alternative means for creating hypervelocity flows.

\section{B. Imaging System and Spectroscopic Setup}

MR configurations were visualized using a schlieren system consisting of a Xenon nanopulser (10 ns duration) white light source and pco.1660 (Cooke Corporation) charge-coupled device (CCD) camera. The system is triggered via the transmitted shock arrival at a $1 \mathrm{MHz}$ response pitot pressure transducer (PCB 113A26)

Table 1 Selected test gas freestream parameters ${ }^{\mathrm{a}}$

\begin{tabular}{lccccccccc}
\hline \hline & $M_{7}$ & $h_{o, 7}, \mathrm{MJ} / \mathrm{kg}$ & Test time, $\mu \mathrm{s}$ & $p_{7, \mathrm{pitot}}, \mathrm{kPa}$ & $p_{7}, \mathrm{~Pa}$ & $u_{t}, \mathrm{~m} / \mathrm{s}$ & $u_{7}, \mathrm{~m} / \mathrm{s}$ & $u_{s}, \mathrm{~m} / \mathrm{s}$ & $T_{7}, \mathrm{~K}$ \\
\hline Experimental & 7.30 & $\overline{7.88}$ & 104 & $53.64 \pm 6.1$ & $\overline{778}$ & $4148 \pm 47$ & $\overline{3}$ & $2044 \pm 42$ & $\overline{644}$ \\
Theoretical & 7.42 & 7.88 & 163 & 55.6 & 778 & 5228 & 3777 & 1995 & 644 \\
\hline \hline
\end{tabular}

a Theoretical calculations assuming one-dimensional, perfect-gas dynamics are compared with experimental measurements. Subscript 7 denotes the test gas. $M$ is the Mach number, $T$ is the static temperature, and $h_{o}$ is the stagnation enthalpy. 


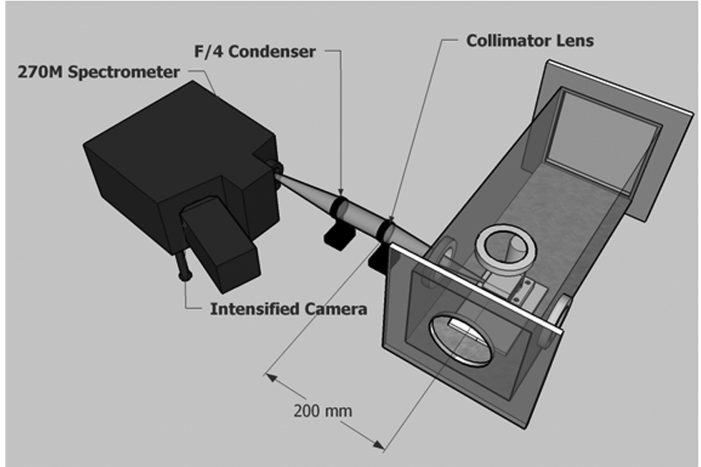

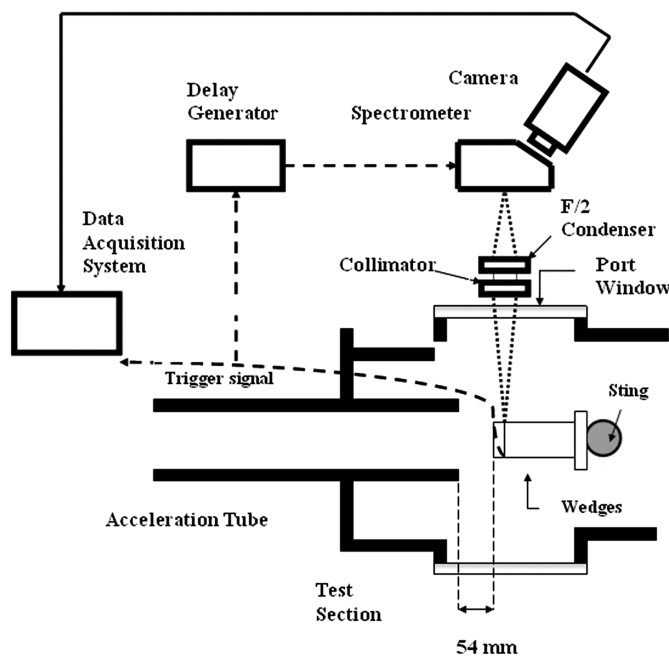

b)

Fig. 1 Experimental setup: a) Three-dimensional schematic of imaging spectroscopy collection system and b) schematic of experimental data acquisition setup.

sting-mounted in the test section $31.75 \mathrm{~mm}$ below the model centerline. Schlieren images and pitot pressure traces from previous experiments [37] and simulations [39] ensure a repeatable and steady MR during the test time.

For the spectroscopic measurements, the broadband emission light is collected and collimated at $90 \mathrm{deg}$ to the vertical axis plane of the test section with a $200 \mathrm{~mm}$ focal length, $50.8 \mathrm{~mm}$ diameter (f/4) UV coated lens (Figs. 1a and 1b). The collimated light is then focused for an imaging spectrograph. Two spectrographs were used in this study: a f / 2 CP140 Jobin Yvon spectrograph for measurements which will be referred to as coarse, and a f/4 270M SPEX spectrograph for measurements which will be referred to as fine. Spectral lines were visualized using a Princeton Instruments PI-MAX MG:512SB intensified CCD camera system and a ST-133 camera controller. For each run, the camera exposure was set to $80 \mu$ s in order to capture as large a portion of the test gas as possible without accelerator or driver gas contamination. For the $f / 4$ 270M SPEX spectrograph measurements, a slit size of $43 \mu \mathrm{m}$ was selected as a compromise between signal strength and resolution. At the focal plane of the spectrometer for the fine measurements, the dispersion across the chip was $0.07 \mathrm{~nm} /$ pixel, corresponding to a wavelength range of $35.71 \mathrm{~nm}$. The measured resolution is $1.4 \AA$. For the coarse measurements, two different slit sizes of 25 and $50 \mu \mathrm{m}$ were used. For the NO wavelength and intensity calibration, a hollow cathode Fe lamp and a L6302 D2 Hamamatsu lamp with Oriel 6310 power supply are used, respectively. For the $\mathrm{OH}$ wavelength and intensity calibration, an Oriel pencil style $6035 \mathrm{Hg}-\mathrm{Ar}$ lamp with a 6045 power supply and a $20 \mathrm{~W}$ Newport 6319 tungsten lamp with a Oriel 68735 power supply are used, respectively. For the coarse resolution results, for which no intensity calibration was performed, the 6035 $\mathrm{Hg}-\mathrm{Ar}$ pencil lamp was the wavelength calibration source.

While emission spectroscopy is referred to as a point measurement, a finite collection volume does exist. In order to determine the one-dimensional (in the axial direction) extent of this imaging point, a calibrated point source was mounted on a translation stage and traversed slightly upstream and downstream while the intensity was recorded. The full-width half-maximum of the recorded intensity profile is $1 \mathrm{~mm}$ with an uncertainty of $\pm 0.25 \mathrm{~mm}$. As with the schlieren system, spectrometer acquisition sequences were triggered using the transmitted shock arrival at the test section pitot probe which was located within the core flow, $31.75 \mathrm{~mm}$ below the tube centerline [37].

\section{Thermochemical Calculations}

The experimental results are compared with calculations using an existing thermochemical model [40], based on the semiclassical, forced-harmonic oscillator model with free-rotating molecule paths by Adamovich and Rich [41], Macheret and Adamovich [42], and Adamovich [43]. The molecule-molecule rates of Adamovich [43] are extended to higher collisional energies by a curve fit function obtained by minimizing the deviation from the numerical integration of the transition probability over all possible $\mathrm{O}_{2}, \mathrm{~N}_{2}$, and $\mathrm{NO}$ transfers. The three-dimensional collisional model of Adamovich and Rich [41] is used for the molecule-atom rates. State-resolved chemical reaction rates are taken from Bose and Candler $[44,45]$. Boltzmann distributions are assumed for NO produced by the first Zeldovich reaction. However, non-Boltzmann distributions are modeled for NO produced by the second Zeldovich reaction [45]. Using the master equation approach of Park [33], a total of 37, 48 , and 40 vibrational levels for $\mathrm{O}_{2}, \mathrm{~N}_{2}$, and $\overline{\mathrm{NO}}$, respectively, are obtained in addition to monatomic $\mathrm{O}, \mathrm{N}$, and Ar, resulting in a 128 species mixture. The extended thermochemical model has been previously validated by comparision with experimentally obtained data for rate constants $[46,47]$, vibrational relaxation times $[48,49]$, dissociation rates $[50,51]$, and vibration-vibration transfer probabilities [52]. Initial inflow conditions for the calculations (static pressure, static temperature, and test gas Mach number) are obtained from inviscid, perfect-gas calculations of expansion tube operation.

\section{Results}

\section{A. Test Gas Freestream Condition}

Table 1 summarizes the test gas freestream condition with a comparison between experimentally measured values and inviscid, one-dimensional, perfect-gas calculations. The experimental values presented are ensemble averaged across a total of 28 separate events, consisting of 20 experiments for $\mathrm{NO}$ spectra acquisition and 8 experiments for $\mathrm{OH}$ spectra acquisition. Across most of the test condition parameters the agreement between theoretical expectation and measurement is very good. The largest discrepancy is seen in the calculated and measured values of the transmitted shock velocity, $u_{t}$. However, two-dimensional Navier-Stokes simulations of a very similar run condition (Air-1) have shown that the transmitted shock is considerably attenuated due to viscous effects through the acceleration section [38]. Good agreement was obtained between the numerically predicted and the experimentally measured velocity. The previous run condition, Air-1, differs from Air-5 (condition used in the current study, see Sec. II.A) only by the primary diaphragm burst pressure. Perfect-gas predictions indicate that the transmitted shock velocity differs by only $1 \%$ for the change in burst pressure. Therefore, $u_{t}$ is assumed to be invariant with burst pressure and the calculated $u_{t}$ over-prediction results from the inviscid, onedimensional assumption. The experimental test gas Mach number is calculated from the measured pitot pressure, $p_{7, \text { pitot }}$, using the 

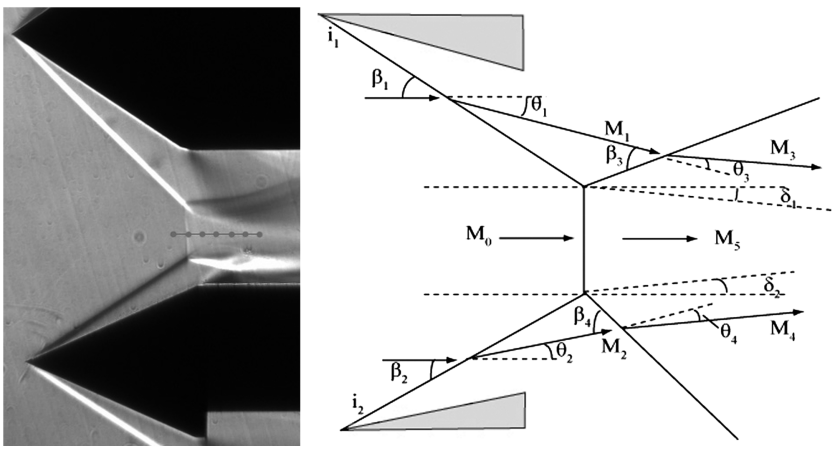

a)

b)

Fig. 2 MR configuration: a) schlieren image of an asymmetric MR in Air-5 test condition, nominal freestream Mach number of 7.42 (wedge tip-to-tip spacing is $24.5 \mathrm{~mm}$, and emission spectroscopy measurement locations are indicated) and b) schematic of an asymmetric MR.

theoretical prediction of the static test gas pressure, $p_{7}$. Very low signal-to-noise ratios prevent experimental measurement of $p_{7}$ for the current run condition. Despite a lower than theoretically predicted test-time, a sufficient slug of test gas exists in which to make spectroscopic measurements.

\section{B. Asymmetric Mach Reflection}

A MR is created by an asymmetric wedge configuration as shown in the schlieren image of Fig. 2a, which displays the Mach stem bridging two triple points from which free shear layers emanate. Twenty-five- and thirty-five-degree half-angle wedges are used with a tip-to-tip separation of $25.4 \mathrm{~mm}$. In order to avoid threedimensional effects, inlet aspect ratios of 1.25 and wedge aspect ratios of 5 were used [53].

The MR has been extensively studied throughout the literature as an example of a shock-shock interaction which occurs extensively in aerodynamic applications. With significant thermochemical effects present in the current study, it is important to characterize their anticipated influence upon the MR configuration. Numerous previous studies have confirmed that the overall MR configuration is displaced forward and the Mach stem height is decreased in the presence of nonequilibrium effects [54-57]. The Mach stem height reduction increases the experimental difficulty as the postshock measurement area is also decreased. Numerical simulations of the current asymmetric wedge arrangement indicate that the flowfield is significantly dependent upon the thermochemical model [39]. Frozen, finite-rate and equilibrium models were examined, for which the finite-rate simulation provided the best agreement with experiment. However, the simulation predicted a slightly further recessed and longer Mach stem than experimentally observed. The simulations also indicated that the Mach stem position is stationary $20 \mu \mathrm{s}$ after the passing of the contact surface. For a test gas duration of approximately $120 \mu$ s this, combined with a consistent triggering event, confirms that a steady MR exists during data collection.

The MR configuration geometry has been verified via measurement of shock angles from the schlieren images. The results are presented in Table 2 and compared against perfect-gas predictions. The subscripts refer to the MR schematic depicted in Fig. 2b. The

Table 2 Comparison between theoretically and experimentally measured MR shock and shear-layer angles

\begin{tabular}{ccc}
\hline \hline $\begin{array}{c}\text { Shock angles, } \\
\text { deg }\end{array}$ & Theoretical & Experimental \\
\hline$\beta_{1}$ & 46.6 & $44.4 \pm 0.3$ \\
$\beta_{2}$ & 33.0 & $32.5 \pm 0.3$ \\
$\beta_{4}$ & 40.6 & $45.1 \pm 0.3$ \\
$\delta_{2}$ & -7.4 & $-2.7 \pm 0.3$ \\
\hline \hline
\end{tabular}

theoretical reflected-shock angles were determined from shock-polar calculations. Comparisons yield very good agreement between incident shock angles. The differences observed for the lower triplepoint reflected-shock and slipstream angles are more pronounced, especially so for the slipstream angle. While the static test gas temperature has not been directly measured, the agreement between test gas pitot pressure, test gas Mach number, primary and transmitted shock speeds, and incident shock angles suggests that freestream conditions are well-predicted by perfect-gas theory.

From schlieren images, the Mach stem is measured to be $3.9 \mathrm{~mm}$ high, almost perpendicular, located $12.7 \mathrm{~mm}$ downstream of the wedge tip plane and its centerline located $2 \mathrm{~mm}$ below the tube axial centerline. As Fig. 2a shows, the uniform region behind the Mach stem which is not influenced by the converging shear-layer slipstreams is very small (approximately $5 \mathrm{~mm}$ ). It is therefore imperative that the spatial locations of the spectra collection points are known very precisely with respect to the wedge tip plane. This involves determining the repeatability of the Mach stem location and potential shift from experiment to experiment. The deviation on both height and location measurements was found to be $\pm 0.5 \mathrm{~mm}$. With an uncertainty of $\pm 0.25 \mathrm{~mm}$ in the imaging location (see Sec. II.B) this results in a combined spatial uncertainty of $\pm 0.75 \mathrm{~mm}$. Repeat experiments show the movement of the Mach stem is small enough with respect to the uniform region length and the Mach stem height such that the calibration imaging point (acquired before the experiment) corresponds to the same location within the flowfield during the experiment. Measurements were made along the Mach stem centerline at $-1,0,1,2,3,4$, and $5 \mathrm{~mm}$ downstream of the Mach stem, locations indicated by the symbols in Fig. 2 a.

Calculations of the expected species concentrations and temperatures in the postshock relaxation region were carried out using the thermochemical model discussed in Sec. III, and are presented in Figs. 3 and 4 . These figures demonstrate the chemical and thermal nonequilibrium nature of the flowfield. The mole fraction profiles up to $5 \mathrm{~mm}$ downstream of the Mach stem for the five major species considered in the model, $\mathrm{NO}, \mathrm{O}_{2}, \mathrm{~N}_{2}, \mathrm{O}$, and $\mathrm{N}$, are shown in Fig. 3. The results predict dissociation behind the normal shock with the presence of NO, O, and N. Figure 4 displays the translational temperature, and the equivalent [40] and A-state vibrational temperatures for $\mathrm{NO}, \mathrm{N}_{2}$, and $\mathrm{O}_{2}$ calculated along the centerline of the Mach stem up to $5 \mathrm{~mm}$ downstream of the Mach stem. The frozen and equilibrium temperatures are calculated to be 7332 and $3872 \mathrm{~K}$, respectively. The A-state vibrational temperature (described as the first vibrational temperature in the Massa and Austin paper) is calculated according to

$$
\frac{e_{1}-e_{0}}{k \log \left(\frac{N_{0}}{N_{1}}\right)}
$$

where $N$ and $e$ denote the mole numbers and energies for the subscripted levels, respectively, and $k$ is the Boltzmann constant [40]. The NO temperatures initially overshoot the frozen temperature.

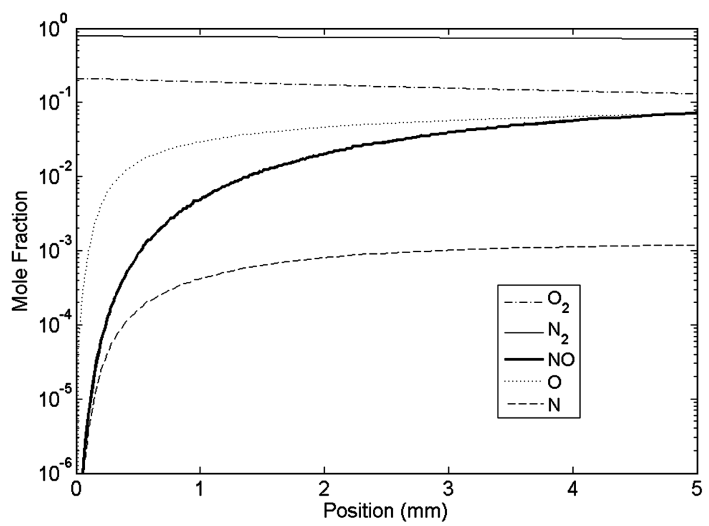

Fig. 3 Calculated mole fraction distributions for five species up to $5 \mathrm{~mm}$ downstream of the Mach stem. 


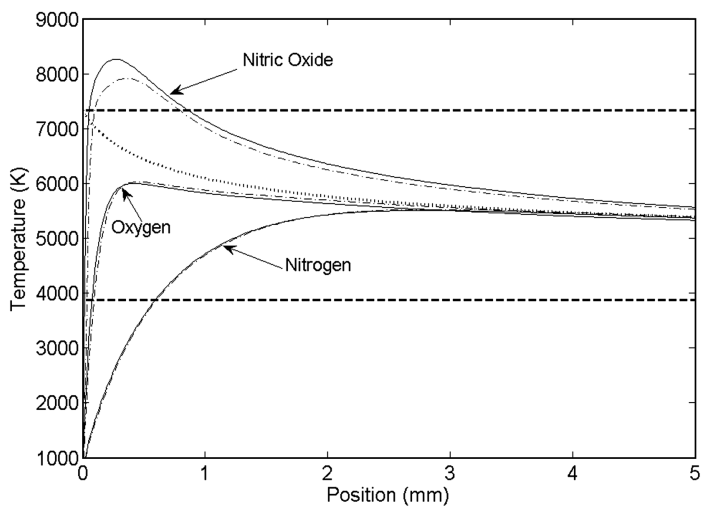

Fig. 4 Temperature profiles up to $5 \mathrm{~mm}$ downstream of the Mach stem. In this figure, the dotted line (thin) represents the translational temperature, the solid (thin) lines represent the equivalent vibrational temperatures of each species, and the dash-dotted (thin) lines represent the A-state vibrational temperatures. The upper and lower dashed (thick) lines show the frozen $(7332 \mathrm{~K})$ and equilibrium $(3872 \mathrm{~K})$ temperatures, respectively.

This behavior is associated with the formation of NO in a nonBoltzmann distribution via the second Zeldovich reaction [44,45]. NO also exhibits the largest difference between the equivalent and A-state vibrational temperatures.

\section{Species Identification}

A spectrum obtained $10 \mathrm{~mm}$ downstream of the Mach stem over the wavelength regime of 200-400 nm using the $f / 2$ CP140 Jobin Yvon spectrograph is shown in Fig. 5. Coarse resolution acquisition was initially undertaken as a means of identifying potential temperature-measurement appropriate species. Only the $50 \mu \mathrm{m}$ results are presented since this resolution provided the largest intensity levels (a $25 \mu \mathrm{m}$ slit was also used). The identified emitters with temperature-fitting potential in this wavelength regime are NO, $\mathrm{OH}$, and $\mathrm{N}_{2}^{+}$. Emission from the $\mathrm{OH}$ radical has the strongest signal and dominates the entire spectrum. Certain portions of the spectrum are magnified in order to show the presence of $\mathrm{N}_{2}^{+}$and NO. Based on these results, the decision was made to concentrate efforts for temperature measurements upon the ultraviolet portion of the spectrum using $\mathrm{OH}$ and $\mathrm{NO}$. Additional measurements also detected no noticeable signatures in the visible region.

$\mathrm{OH}$ is present in the flowfield due to moisture contamination in the air test gas. As discussed in Sec. I, NO and $\mathrm{OH}$ spectral data have previously been the focus of a series flight experiments measuring ultraviolet emission behind a bow shock. Calculations for these experiments showed the presence of trace amounts of water vapor did not affect the density, temperature, and major species $\left(\mathrm{N}_{2}, \mathrm{O}_{2}, \mathrm{NO}, \mathrm{N}\right.$, O) concentrations behind the shock [4]. In the present work, to check

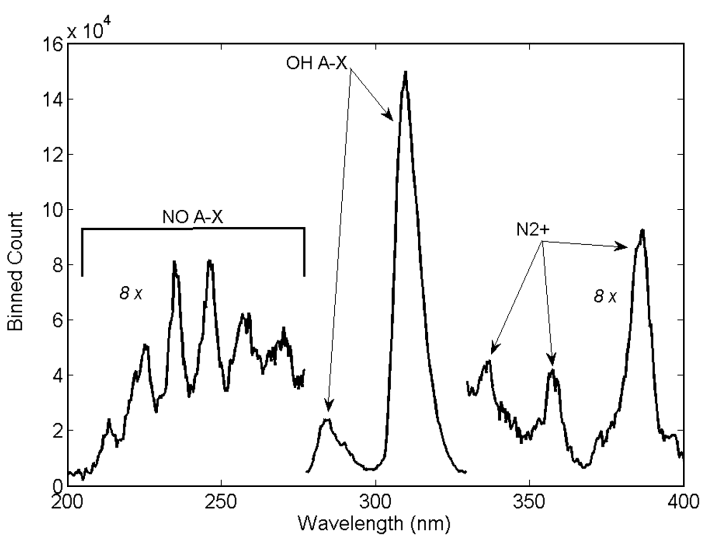

Fig. 5 Spectrum obtained $10 \mathrm{~mm}$ downstream of the Mach stem with a $50 \mu \mathrm{m}$ slit and $50 \mu$ s exposure time with certain portions of the spectrum magnified. the presence of water vapor or associated radical species had no measurable effect on the temperature measurements, experiments were carried out with both dry (bottled) and moist (room) air.

\section{OH Results}

Because of the strong signal strength, initial measurements were conducted using the emission spectra of $\mathrm{OH}$. The $\mathrm{OH} A-X$ band calibration setup was also easier to implement than the NO $A-X$ band as a traditional blackbody radiation source with analytical solution could be used. The location of data collection with respect to the MR are shown in Fig. 2a. No signal was observed at the $-1 \mathrm{~mm}$ location upstream of the Mach stem.

Fine-scale spectra were collected and temperature fits constructed for the $A^{2} \sum^{+} \rightarrow X^{2} \prod$ electronic transition in the 307-320 region. An example of an emission spectrum for the $\mathrm{OH} A-X$ band obtained $4 \mathrm{~mm}$ downstream of the Mach stem is shown in Fig. 6. Simulated and experimentally observed spectra are compared. At each axial location, LIFBASE [58] was used to generate simulated spectra across a broad temperature range at coarse temperature increments of $100 \mathrm{~K}$ using Lorentzian profiles and a resolution of $0.14 \mathrm{~nm}$. Wavelengths were interpolated so that the LIFBASE data points matched up with the experimental points and at each temperature increment a scaling factor was computed which reduces the residual, a value defined to be the sum of the differences between experimental and predicted intensity peak values across the entire spectral range. The smallest residual of the entire temperature range provided the fit vibrational temperature. The rotational and translational energy modes are assumed to be in equilibrium. Once the coarse temperature was determined, further optimization was performed such that the final temperature increment was $20 \mathrm{~K}$. This final simulation uncertainty of $20 \mathrm{~K}$ is deemed appropriate as it is small compared with typical temperature uncertainty values arising from the major sources of experimental error (see Sec. IV.F), independent of the spatial location of the measurement. As shown by Fig. 6, the results indicate that the intensities across the entire spectrum match up very well and that reasonable temperature fits have been achieved. Spectra collected at $1 \mathrm{~mm}$ upstream of the Mach stem yielded no signal, confirming the spatial precision of the imaging location technique and lack of freestream dissociation in the facility.

\section{E. NO Results}

Experiments were undertaken in order to investigate the NO $\gamma$ band. Since this is a nonequilibrium flowfield, it should be noted that there are multiple vibrational temperatures associated with the different electronic states of the nitric oxide molecule. Figure $\underline{7}$ is an example of three NO spectra at three different streamwise locations of 2,3 , and $4 \mathrm{~mm}$ downstream from the Mach stem. The signal strength is observed to attenuate markedly with increasing axial distance.

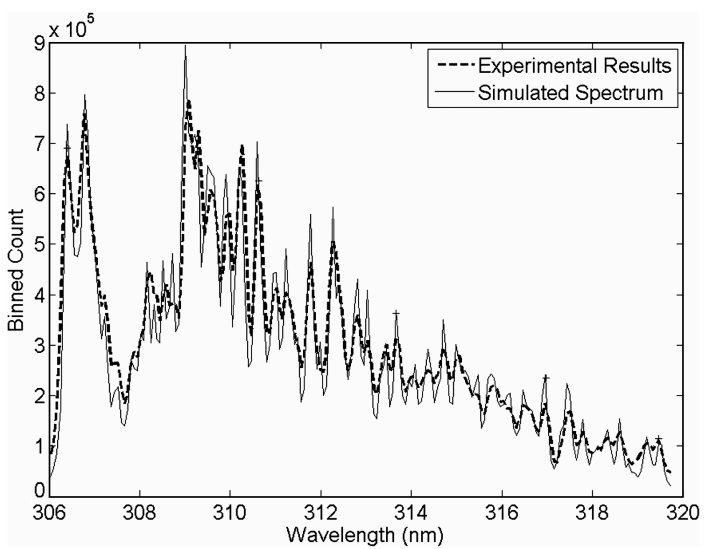

Fig. 6 Simulated LIFBASE and experimental $\mathrm{OH}$ spectra obtained 4 $\mathrm{mm}$ downstream of the Mach stem for a vibrational temperature of $4140 \mathrm{~K}$. 


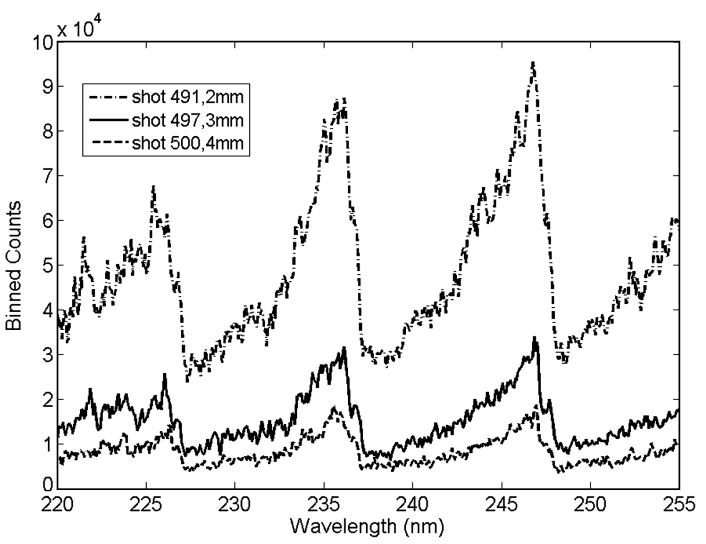

Fig. 7 NO $\gamma$ band spectra obtained at three different locations $(2,3$, and $4 \mathrm{~mm}$ ) downstream of the Mach stem.

Spectral fitting to the NO data using LIFBASE yielded very high temperatures, possibly due to the LIFBASE rotational and vibrational quantum number limits of 80 and 5, respectively. Calculations across an appropriate temperature range revealed that nonnegligible Boltzmann rotational and vibrational populations exist for NO above these limits. Hence, an in-house algorithm developed by Glumac with user-defined maximum limits was used to generate simulated spectra. Vibrational and rotational energies are determined to the third- and second-order, respectively, via Dunhamtype potential expansions. For consistency, the spectroscopic constants used in these expansions are taken as those from LIFBASE [58] and are summarized in Appendix A. For the doublet ground state, the lower and upper configuration energies are calculated using the analytical expressions of Kovacs [59]. The dependence of the spin-orbit parameter, $A$, upon the vibrational quantum number is taken from Amiot [60]. Line strengths were calculated via multiplication of the Franck-Condon factors and the Hönl-London factors. The Hönl-London factors for the doublet transitions were determined following the expressions of Kovacs [59] and the Franck-Condon factors were taken from Ory et al. [61]. Conversion from vacuum to air wavelengths is achieved via the Edlen formula. The LIFBASE simulation formulates emission intensity as a function of molecule lifetime, emission coefficients, and predissociation rates. LIFBASE calculates the emission coefficients by incorporating the Hönl-London factors and the transition probabilities that are calculated using the Rydberg-Klein-Ress method. The predissociation phenomena has been observed for the NO $\gamma$ band and has been experimentally [62], theoretically [63], and numerically [64] shown to be dependent upon both vibrational and rotational quantum numbers. Vibrational levels of $v^{\prime}=4$ and 5 can predissociate and for $v^{\prime}=3$, rotational levels above $N^{\prime}=25$ can predissociate [62]. However, for the most part transitions from these levels result in

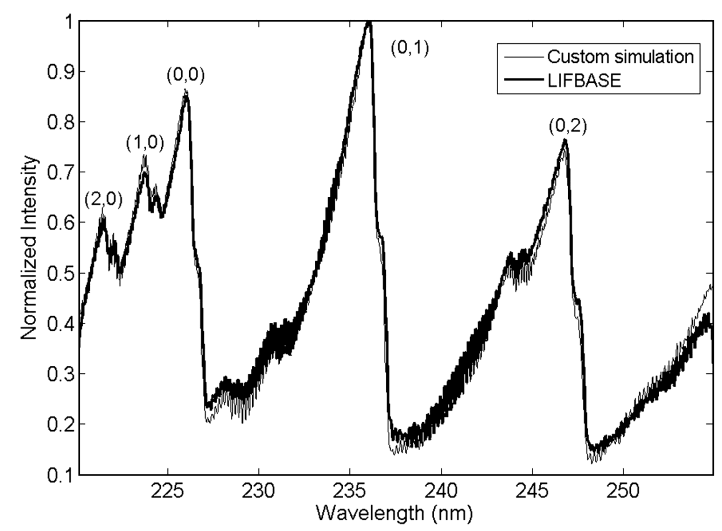

Fig. 8 Comparison between simulated spectra using an in-house developed algorithm and LIFBASE for an A-state vibrational temperature of $6200 \mathrm{~K}$. $v_{\max }=5$ and $J_{\max }=80$. The major vibrational band transitions are indicated.

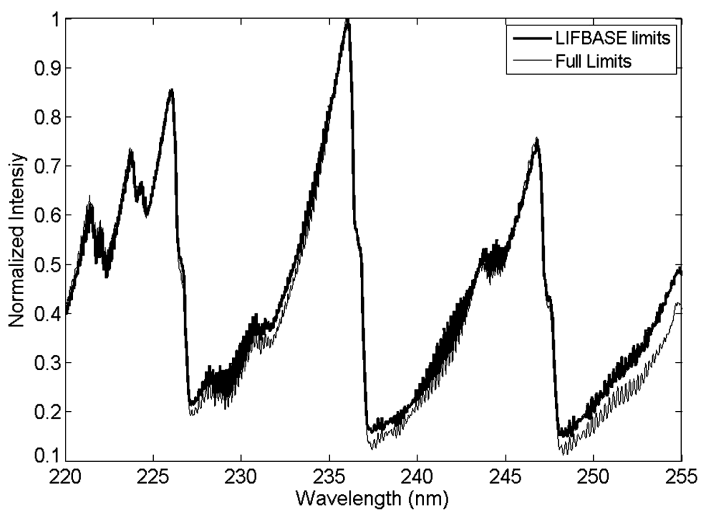

Fig. 9 Comparison between the results of two simulated spectra using an in-house developed algorithm, one with $v_{\max }=5$ and $J_{\max }=80$ (limits inherent in LIFBASE), and the other with the extended limits of $J_{\max }=20$ and $J_{\max }=250$.

energies outside the current wavelength regime. As identified by Fig. $\underline{8}$, the dominant vibrational transitions which weigh heavily upon the temperature-fitting procedure will not predissociate as explained above. Furthermore, LIFBASE simulations for 220 $255 \mathrm{~nm}$ show no difference between spectra with and without predissociation broadening. Therefore, predissociation is not considered to be a phenomena which needs to be considered for the wavelength range of interest. Spectroscopic constants and expressions used within the inhouse simulation are outlined in Table A1.

Figure $\underline{8}$ shows a comparison between LIFBASE and an in-house simulation for a temperature of $6200 \mathrm{~K}$ for limits of $v_{\max }=5$ and $J_{\max }=80$ (limits inherent to LIFBASE). The major vibrational band transitions are also indicated. The spectra are normalized by the maximum intensity in each case, which corresponds to the $(0,1)$ peak value. The agreement between the two simulations is very good and within the experimental spectral resolution. Figure 9 shows a comparison between the two in-house simulations, one with the lower limits of $v_{\max }=5$ and $J_{\max }=80$ and the other with the extended limits of $v_{\max }=20$ and $J_{\max }=250$. As evident in the figure, the use of the extended limits alters the intensity distribution across major portions of the spectrum. The extended vibrational limits (and hence larger $\Delta v$ values) will not influence the simulated spectrum, however, the modeling of extra rotational levels will alter the spectrum within the $220-255 \mathrm{~nm}$ range. Since the intensity distribution is the optimization parameter for the temperature-fitting procedure, the inclusion of additional limits via the in-house simulations is justified.

Fine-scale spectra were collected and temperature fits constructed for the NO $A^{2} \sum^{+} \rightarrow X^{2} \prod$ electronic transition in the $220-255 \mathrm{~nm}$ region using the extended limits. The temperature-fitting procedure was the same as described for the $\mathrm{OH} A-X$ transition. NO spectra

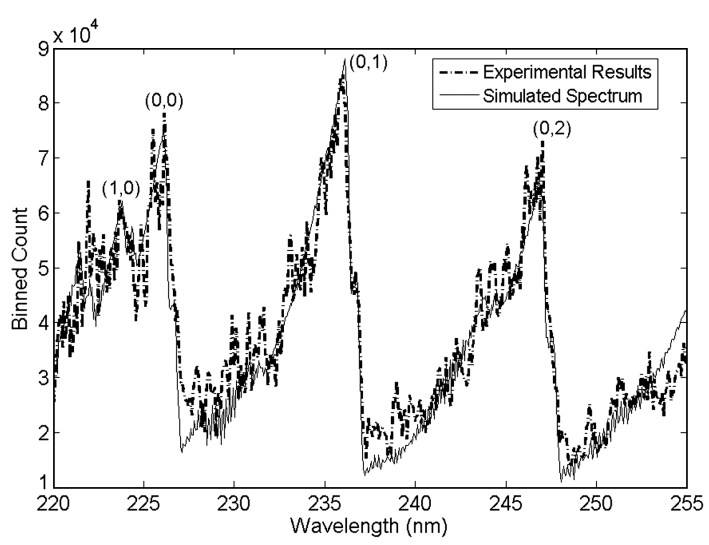

Fig. 10 Simulated and experimental NO spectra obtained $2 \mathrm{~mm}$ downstream of the Mach stem for an A-state vibrational temperature of $6900 \mathrm{~K}$. 


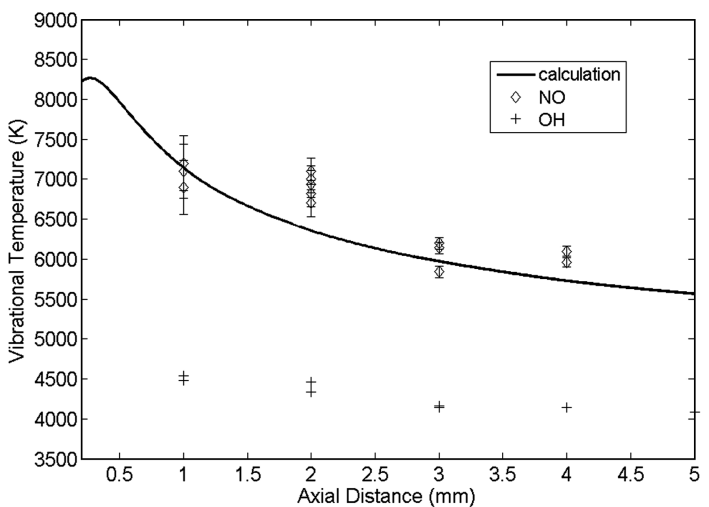

Fig. 11 Experimentally measured NO and $\mathrm{OH}$ A-state vibrational temperatures in the postshock relaxation region. Measurements are compared with calculations using a detailed thermochemical model.

were collected at 1, 2, 3, and $4 \mathrm{~mm}$ downstream of the Mach stem. Further downstream spectral acquisition of the relaxation region was restricted by the influence of converging shear layers bounding the measurement region, as shown in Fig. 2a. A sample spectrum, collected at $2 \mathrm{~mm}$ behind the Mach stem, is shown in Fig. 10 along with the simulated comparison. The vibrational temperature in this case was determined to be $6900 \mathrm{~K}$. Using the LIFBASE limits, the calculated vibrational temperature was $7600 \mathrm{~K}$. As exhibited for all imaging locations, the NO spectra are somewhat noisy and the visual fit fidelity is not as pronounced as in the $\mathrm{OH}$ spectra. As shown in Fig. 10, the major vibrational band transition intensities are all accurately matched.

The potential of contaminant emission within the $220-255 \mathrm{~nm}$ range was further investigated. Previous spectroscopic measurements at the TCM2 hypersonic facility have highlighted the importance of reducing test gas contamination. Pilverdier et al. noticed that a Mylar secondary diaphragm displayed significantly less emissive intensity than one made from copper [34]. The HET facility operates with a Mylar diaphragm. Ramjuan et al. also emphasized the importance of cleaning the facility [36]. As a result, before each shot both the driven and accelerator section were cleaned. No differences in the nitric oxide spectra were observed.

Dry air was also used as the test gas in order to see if the trace quantities of water vapor were affecting the results. The test location $2 \mathrm{~mm}$ behind the Mach stem was used to determine the influence of the moisture within the air. At this location five room air shots and six dry air shots were conducted and the temperatures determined. The standard deviation of these determined temperatures was 320 and $140 \mathrm{~K}$ for the room air and dry air runs, respectively. Despite the improvement in shot-to-shot repeatability with dry air as the test gas,

Table 3 Comparison between averaged experimental values and numerical results at different locations behind the Mach stem

\begin{tabular}{ccc}
\hline \hline Distance, mm & Numerical, K & Experimental, K \\
\hline 1 & 7143 & 7067 \\
2 & 6356 & 6917 \\
3 & 5971 & 6060 \\
4 & 5721 & 6007 \\
\hline \hline
\end{tabular}

no marked change in the experimental spectra was observed. Previous studies had identified $\mathrm{O}_{2}$ Schumann-Runge band radiation within the $\mathrm{NO} \gamma$ band emission, however, its presence was not seen to influence the measurement $[25,26]$. Irregardless of any contaminant source, the intensity of the $\mathrm{NO}$ emission dominates the spectrum and is significantly greater than the contaminant signal. Therefore, as the temperature-fitting procedure uses intensity peak values as the main optimization parameter, the contaminant signal is not sufficient enough to hamper the temperature calculation.

Experimentally measured NO vibrational temperatures are shown in Fig. 11. Data are obtained from three experiments each at 1,3, and $4 \mathrm{~mm}$ and six experiments at the $2 \mathrm{~mm}$ location. The repeatability of the measurements is good. The temperature profile calculated using the thermochemical model detailed above is also shown. Very good agreement is achieved between calculated and experimentally measured vibrational temperatures across the relaxation region. The largest discrepancy is observed at the $2 \mathrm{~mm}$ location, while the temperature measurements at the other three locations are all within experimental error. The equilibrium temperature for this test condition (assuming a nitrogen, oxygen, and argon air mixture) is calculated to be $3872 \mathrm{~K}$ from the NASA Chemical Equilibrium with Applications program [65]. Table 3 compares the ensemble average of the temperature measurement at each location versus the numerical result.

Results from the $\mathrm{OH}$ temperature fits described above are also presented on the same graph. The $\mathrm{OH}$ vibrational temperatures are considerably lower than those of NO and the temperature gradient throughout the relaxation region is much less pronounced and accompanied by a faster relaxation rate. $\mathrm{OH}$ error bars are not presented as no thermochemical calculation was conducted and hence no temperature gradient was available. The disparity between the experimentally measured $\mathrm{OH}$ and $\mathrm{NO}$ vibrational temperatures is indicative of the nonequilibrium flowfield. The deviation from equilibrium of each of the two species depends on the specificity of the reactions that lead to their formation. As discussed in Sec. I, OH $A-X$ band vibrational temperatures calculated from $\mathrm{OH}$ radiation models have previously been reported to differ substantionally from bulk vibrational temperatures. For example, Levin et al. calculated the peak stagnation line vibrational $\mathrm{OH}$ A-state temperature to be two- to three-times greater than the bulk flow vibrational temperature [7]. Kossi and Boyd also found considerable differences between the vibrational temperatures of the bulk flow and those calculated from an $\mathrm{OH} A-X$ radiation model [12]. The production mechanisms of $\mathrm{OH}$ and their impact on the vibrational temperature of the nascent species were found to be significant by Gimelshein et al [11]. Additionally, it was seen that even for a given production mechanism, different vibrational temperatures were predicted depending on the chemical reaction model [13]. These previous studies, together with the present work, indicate that while $\mathrm{OH}$ is an attractive species to probe due to its single, significantly excited state at these conditions, there are challenges associated with its use in nonequilibrium flows. However, the presented $\mathrm{OH}$ results serve as useful comparative experimental data towards resolving these issues and verifying any $\mathrm{OH}$ inclusive thermochemical model.

\section{F. Sources of Uncertainty}

The temperature-measurement sources of error arise from shot-toshot variation in MR location, the spatial precision of the imaging location, test condition variability, spectroscopic resolution, and the

Table 4 Breakdown of the contribution of the different uncertainty sources at each spatial imaging location for the nitric oxide vibrational temperature measurements-

\begin{tabular}{cccccc}
\hline $\begin{array}{c}\text { Axial distance, } \\
\text { mm }\end{array}$ & $\begin{array}{c}\text { Spectrograph } \\
\text { resolution }\end{array}$ & MR & $\begin{array}{c}\text { Imaging } \\
\text { location }\end{array}$ & $\begin{array}{c}\text { Test } \\
\text { condition }\end{array}$ & $\begin{array}{c}\text { Temperature } \\
\text { increment }\end{array}$ \\
\hline 1 & 0.16 & 77.76 & 19.44 & 2.55 & 0.09 \\
2 & 0.15 & 75.45 & 18.86 & 5.17 & 0.37 \\
3 & 0.13 & 63.52 & 15.88 & 18.67 & 1.81 \\
4 & 0.11 & 56.67 & 14.17 & 25.25 & 2.80 \\
\hline \hline
\end{tabular}

${ }^{a}$ Values are given as percentages of the total uncertainty. 
temperature increment selection of the fit to simulated spectra. The first two sources are dependent upon the relaxation region temperature gradient, which was determined from numerical calculations. As described in Secs. II.B and IV.B, the uncertainties in the imaging location and MR movement are 0.25 and $0.5 \mathrm{~mm}$, respectively. The freestream static temperature was used as the parameter to gauge test condition variability. For the purpose of the uncertainty analysis, the freestream static temperature is taken to be only dependent upon the HET initial pressures. Theoretically, the freestream static temperature would also be dependent upon the section gas compositions. As discussed above in Sec. II.A, the air leak-rate into the helium filled expansion section is negligible and hence will not influence the gas dynamic prediction. Moisture within the air is expected to have a negligible influence upon the air test gas and is also not considered. Driver pressures are so large (roughly $25 \mathrm{~atm}$ ) that any residual air within the helium gas is completely negligible. Therefore, freestream static temperatures are taken to be dependent only upon the initial HET pressures. Table 4 presents the percentage breakdown of each uncertainty source. The temperaturemeasurement error bars at each imaging location, $\Delta T$, based upon the five uncertainty parameters described above is calculated using the following equation:

$$
\Delta T=\sqrt{\sum_{i=1}^{5}\left[\left(\frac{\partial T}{\partial x_{i}} \omega_{x_{i}}\right)^{2}\right]}
$$

where $\omega_{x_{i}}$ denotes the uncertainty in the measurement of a certain parameter, $x_{i}$. Values are presented as percentages of the total uncertainty. The largest contribution to the total uncertainty is due to the MR movement from shot-to-shot. Combined with the imaging location uncertainty, these two factors account for more than $70 \%$ of the total uncertainty at each spatial location.

\section{Conclusions}

Emission spectroscopy is used to measure nitric oxide and hydroxyl radical vibrational temperatures behind a strong normal shock. The stationary normal shock is created via a MR using an opposing wedge model in a high-enthalpy Mach 7.42 air freestream in an expansion tube facility. The inflow conditions for the normal shock have been experimentally defined by pressure, velocity, and shock angle measurements. Experimental spectral data from the NO and $\mathrm{OH} A-X$ band sequences were collected at selected locations, $1 \mathrm{~mm}$ apart, behind the Mach stem. $\mathrm{OH}$ temperature fits were conducted using simulated spectra generated by LIFBASE, whereas the NO fits required higher vibrational and rotational levels and the use of an in-house spectral simulation algorithm. A state-resolved thermochemical model was used to calculate the NO A-state temperature profile up to $5 \mathrm{~mm}$ downstream of the Mach stem. Very good agreement is obtained between NO vibrational measurements and computations. As has been reported for previous studies of flight data, the temperatures calculated from $\mathrm{OH}$ emission differ significantly from those of other species in these nonequilibrium flows. These results extend previous studies applying emission spectroscopy for test gas identification in impulse facilities and demonstrate the measurement of species vibrational temperatures in an expansion tube.

Table A1 Spectroscopic constants used in the current study

\begin{tabular}{ccc}
\hline \hline Constant & $\mathrm{NO} X^{2} \prod$ & $\mathrm{NO} A^{2} \sum^{+}$ \\
\hline$\omega_{e}$ & 1904.13455 & 2374.372 \\
$\omega_{e} x_{e}$ & 14.088358 & 16.159 \\
$\omega_{e} y_{e}$ & 0.0100467 & 0.0373 \\
$B_{e}$ & 1.70488847 & 1.995586 \\
$\alpha_{e}$ & 0.01754158 & 0.018714 \\
\hline \hline
\end{tabular}

\section{Appendix: Spectroscopic Calculations}

The expressions used for the vibrational energy, $G(v)$, and rotational energy, $F_{v}(J)$, are

$$
\begin{gathered}
F_{v}(J)=B_{v} J(J+1) \\
G(v)=\omega_{e}(v+1 / 2)-\omega_{e} x_{e}(v+1 / 2)^{2}+\omega_{e} y_{e}(v+1 / 2)^{3} \\
B_{v}=B_{e}-\alpha_{e}(v+1 / 2)
\end{gathered}
$$

\section{Acknowledgment}

This research was funded in part through the Air Force Office of Scientific Research/Multi-University Research Initiative Grant FA9550-04-1-0425 with John Schmisseur as Technical Monitor.

\section{References}

[1] Wen, C. Y., and Hornung, H. G., "Nonequilibrium Dissociating Flow Over Spheres," Journal of Fluid Mechanics, Vol. 299, 1995, pp. 389 405 .

doi:10.1017/S0022112095003545

[2] Candler, G. V., Mavriplis, D. J., and Trevino, L., "Current Status and Future Prospects for the Numerical Simulation of Hypersonic Flows," AIAA Paper 2009-153, Jan. 2009.

[3] Erdman, P. W., Zipf, E. C., Howlett, L. C., Levin, D. A., Collins, R. J., and Candler, G. V., "Flight Measurements of Low-Velocity Bow Shock Ultraviolet Radiation," Journal of Thermophysics and Heat Transfer, Vol. 7, No. 1, 1993, pp. 37-41. doi: $10.2514 / 3.11566$

[4] Levin, D. A., Candler, G. V., Collins, R. J., Erdman, P. W., Zipf, E., Espy, P., and Howlett, C., "Comparison of Theory with Experiment for the Bow Shock Ultraviolet Rocket Flight," Journal of Thermophysics and Heat Transfer, Vol. 7, No. 1, 1993, pp. 30-36. doi: $10.2514 / 3.11565$

[5] Levin, D. A., Candler, G. V., Collins, R. J., Erdman, P. W., Zipf, E. C., and Howlett, L. C., "Examination of Theory for Bow Shock Ultraviolet Rocket Experiments, 1," Journal of Thermophysics and Heat Transfer, Vol. 8, No. 3, 1994, pp. 447-452. doi: $10.2514 / 3.563$

[6] Levin, D. A., Candler, M. B. G. V., Collins, R. J., and Smith, G. P., "Examination of Theory for Bow Shock Ultraviolet Rocket Experiments, 2," Journal of Thermophysics and Heat Transfer, Vol. 8, No. 3, 1994, pp. 453-459. doi: $10.2514 / 3.564$

[7] Levin, D. A., Collins, R. J., Candler, G. V., Wright, M. J., and Erdman, P. W., "Examination of OH Ultraviolet Radiation from Shock-Heated Air," Journal of Thermophysics and Heat Transfer, Vol. 10, No. 2, 1996, pp. 200-208. doi: $10.2514 / 3.776$

[8] Levin, D. A., Candler, G. V., and Collins, R. J., "Overlay Method for Calculating Excited State Species Properties in Hypersonic Flows," AIAA Journal, Vol. 35, No. 2, 1997, pp. 288-294. doi: $10.2514 / 2.90$

[9] Levin, D. A., Laux, C. O., and Kruger, C. H., "A General Model for the Spectral Calculation of OH Radiation in the Ultraviolet," Journal of Quantitative Spectroscopy and Radiative Transfer, Vol. 61, No. 3, 1999, pp. 377-392. doi:10.1016/S0022-4073(98)00024-7

[10] Levin, D. A., Gimelschein, S. F., and Gimelschein, N. E., "Examination of Water Dissociation Models in Shock-Heated Air," Journal of Thermophysics and Heat Transfer, Vol. 16, No. 2, 2002, pp. 251-260. doi: $10.2514 / 2.6675$

[11] Gimelschein, N. E., Levin, D. A., and Gimelschein, S. F., "Hydroxyl Formation Mechanisms and Models in High-Altitude Hypersonic Flows," AIAA Journal, Vol. 41, No. 7, 2003, pp. 1323-1331. doi: $10.2514 / 2.2077$

[12] Kossi, K. K., and Boyd, I. D., "Detailed Computation of Ultraviolet Spectra in Rarefied Hypersonic Flow," Journal of Spacecraft and Rockets, Vol. 35, No. 5, 1998, pp. 653-659. doi: $10.2514 / 2.3381$

[13] Levin, D. A., Gimelschein, S. F., and Gimelschein, N. E., "QuasiClassical Trajectory Modeling of OH Production in Direct Simulation Monte Carlo," Journal of Thermophysics and Heat Transfer, Vol. 19, 
No. 2, 2005, pp. 235-244.

doi: $10.2514 / 1.9787$

[14] Nerem, R. M., Carlson, L. A., and Hartsel, J. E., "Chemical Relaxation Phenomena Behind Normal Shock Waves in a Dissociated Freestream,' AIAA Journal, Vol. 5, No. 5, 1967, pp. 910-916.

[15] Russo, A. L., "Spectrophotometric Measurements of the Vibrational Relaxation of $\mathrm{CO}$ in Shock-Wave and Nozzle Expansion-Flow Environments," Journal of Chemical Physics, Vol. 47, No. 12, 1967, pp. 5201-5210.

doi: $10.1063 / 1.1701780$

[16] Moser, L. K., and Hindelang, F. J., "Vibrational Relaxation of NO Behind Shock Waves," Experiments in Fluids, Vol. 7, No. 1, 1989, pp. 67-69.

[17] Moser, L. K., and Hindelang, F. J., "Shock-Tube Study of the Vibrational Relaxation of Nitric Oxide," 17th International Symposium on Shock Waves and Shock Tubes, AIP, Bethlehem, PA, 1990, pp. 531536.

[18] Sharma, S. P., and Gillespie, W., "Nonequilibrium and Equilibrium Shock Front Radiation Measurements," Journal of Thermophysics and Heat Transfer, Vol. 5, No. 3, 1991, pp. 257-265. doi: $10.2514 / 3.259$

[19] Allen, R. A., Keck, J. C., and Camm, J. C., "Nonequilibrium Radiation from Shock Heated Nitrogen and a Determination of the Recombination Rate," AVCO-Everett Research Lab., Rept. 110, 1961.

[20] Allen, R. A., "Nonequilibrium Shock Front Rotational, Vibrational and Electronic Temperature Measurements," AVCO-Everett Research Lab., Rept. 1986, 1964.

[21] Allen, R. A., Keck, J. C., and Camm, J. C., "Radiation from Hot Nitrogen," AVCO-Everett Research Lab., Rept. 102, 1961.

[22] Labracherie, L., Billiotte, M., and Houas, L., "Nonequilibrium Determination of Temperature Proles by Emission Spectroscopy," Journal of Quantitative Spectroscopy and Radiative Transfer, Vol. 54, No. 3, 1995, pp. 573-579. doi:10.1016/0022-4073(95)00027-I

[23] Ramjuan, D., Dumitrescu, M., and Brun, R., "Kinetics of Free Radicals Behind Strong Shock Waves," Journal of Thermophysics and Heat Transfer, Vol. 13, No. 2, 1999, pp. 219-225. doi: $10.2514 / 2.6439$

[24] Rond, C., Boubert, P., Felio, J. M., and Chikhaoui, A., "Nonequilibrium Radiation Behind a Strong Shock Wave in $\mathrm{CO}_{2}-\mathrm{N}_{2}$," Journal of Chemical Physics, Vol. 340, Nos. 1-3, 2007, pp. 93-104. doi:10.1016/j.chemphys.2007.08.003

[25] Wurster, W. H., Treanor, C. E., and Williams, M. J., "Nonequilibrium UV Radiation and Kinetics Behind Shock Waves in Air," AIAA Paper 1989-1918, 1989.

[26] Wurster, W. H., Treanor, C. E., and Williams, M. J., "Kinetics of UV Production Behind Shock Waves in Air," AIAA Paper 1990-1666, 1990.

[27] Babikian, D. S., Gopaul, N. K. J. M., and Park, C., "Measurement and Analysis of Nitric Oxide Radiation in an Arcjet Flow," Journal of Thermophysics and Heat Transfer, Vol. 8, No. 4, 1994, pp. 737-743. doi: $10.2514 / 3.606$

[28] Park, C. S., Neweld, M. E., Fletcher, D. G., and Goekcen, T., "Spectroscopic Measurements of Shock-Layer Flows in an Arcjet Facility," Journal of Thermophysics and Heat Transfer, Vol. 13, No. 1, 1999, pp. 60-67. doi: $10.2514 / 2.6401$

[29] Park, C. S., Neweld, M. E., Fletcher, D. G., Goekcen, T., and Sharma, S. P., "Spectroscopic Emission Measurements Within the Blunt-Body Shock Layer in an Arcjet Flow," Journal of Thermophysics and Heat Transfer, Vol. 12, No. 2, 1998, pp. 190-197. doi: $10.2514 / 2.6344$

[30] Staack, D., Farouk, B., Gutsol, A. F., and Fridman, A. A., "Spectroscopic Studies and Rotational and Vibrational Temperature Measurements of Atmospheric Pressure Normal Glow Plasma Discharges In Air," Plasma Sources Science and Technology, Vol. 15, No. 4, 2006, pp. 818-827. doi:10.1088/0963-0252/15/4/027

[31] Holden, M. S., and Candler, G. V., "Experimental Studies in the LENS Shock Tunnel and Expansion Tunnel to Rxamine Real-Gas Effects in Hypervelocity Flows," AIAA Paper 2004-0916, Jan. 2004.

[32] Nompelis, I., Candler, G. V., and Holden, M. S., "Effect of Vibrational Nonequilibrium on Hypersonic Double-Cone Experiments," AIAA Journal, Vol. 41, No. 11, 2003, pp. 2162-2169. doi: $10.2514 / 2.6834$

[33] Park, C., "Thermochemical Relaxation in Shock Tunnels," Journal of Thermophysics and Heat Transfer, Vol. 20, No. 4, 2006, pp. 689-698.

[34] Pilverdier, H., Brun, R., and Dumitrescu, M. P., "Emission and Raman Spectroscopy Measurements in Hypersonic Nitrogen Flows," Journal of Thermophysics and Heat Transfer, Vol. 15, No. 4, 2001, pp. 484 490.

doi:10.2514/2.6637

[35] Boubert, P., Chaiz, A., Chikhaoui, A., Robin, L., and Versich, P., "Aerodynamic Calibration of TCM2 Facility and Study of a Bow Shock Layer by Emission and Laser Spectroscopy," Shock Waves, Vol. 11, No. 5, 2002, pp. 341-351. doi:10.1007/s001930100117

[36] Ramjuan, D., Sasoh, A., Ohnishi, Y., and Takayama, K., "TimeResolved Spectroscopy in the Shock Layer of a Blunt Body Placed in an Expansion Tube Flow," 24th International Congress on High-Speed Photography and Photonics, Vol. 4183, Society of Photographic Instrumentation Engineers, Sendai, Japan, 2001.

[37] Dufrene, A., Sharma, M., and Austin, J. M., "Design and Characterization of a Hypervelocity Expansion Tube Facility," Journal of Propulsion and Power, Vol. 23, No. 6, 2007, pp. 1185-1193. doi:10.2514/1.30349

[38] McGilvray, M., Austin, J. M., Sharma, M., Jacobs, P. A., and Morgan, R. G., "Diagnostic Modelling of an Expansion Tube Operating Condition," Shock Waves, Vol. 19, No. 1, 2009, pp. 59-66. doi:10.1007/s00193-009-0187-9

[39] McGilvray, M., Austin, J. M., Sharma, M., Jacobs, P. A., and Morgan, R. G., "Diagnostic Modelling of an Expansion Tube Operating Condition for a Hypersonic Shear Layer Experiment," Proceedings of the 16th Australasian Fluid Mechanics Conference, School of Engineering, Univ. of Queensland, Gold Coast, Australia, 2007.

[40] Massa, L., and Austin, J. M., "Spatial Linear Stability of a Hypersonic Shear Layer with Nonequilibrium Thermochemistry," Physics of Fluids, Vol. 20, No. 8, 2008, pp. 84-104.

[41] Adamovich, I., and Rich, J., "Three Dimensional Nonperturbative Analytical Model of Vibrational Energy Transfer in Atom-Molecule Collisions," Journal of Chemical Physics, Vol. 109, No. 18, 1998 , pp. 7711-7724. doi: $10.1063 / 1.477417$

[42] Macheret, S., and Adamovich, I., "Semiclassical Modelling of State Specific Dissociation Rates in Diatomic Gases," Journal of Chemical Physics, Vol. 113, No. 17, 2000, pp. 7351-7361. doi:10.1063/1.1313386

[43] Adamovich, I., "Three Dimensional Analytical Model of Vibrational Energy Transfer in Molecule-Molecule Collisions," AIAA Journal, Vol. 39, No. 10, 2001, pp. 1916-1925. doi: $10.2514 / 2.1181$

[44] Bose, D., and Candler, G. V., "Thermal Rate Constants of the $\mathrm{N}_{2}+$ $\mathrm{O} \rightarrow \mathrm{NO}+\mathrm{N}$ Reaction Using Ab Initio Potential Energy Surfaces,' Journal of Chemical Physics, Vol. 104, No. 8, 1996, pp. 2825-2833. doi:10.1063/1.471106

[45] Bose, D., and Candler, G. V., "Thermal Rate Constants of the $\mathrm{O}_{2}+$ $\mathrm{N} \rightarrow \mathrm{NO}+\mathrm{O}$ Reaction Based on Ab Initio Potential Energy Surfaces,' Journal of Chemical Physics, Vol. 107, No. 16, 1997, pp. 6136-6145. doi:10.1063/1.475132

[46] Kolesnick, G. D. B. R. E., "Vibrational Relaxation of Oxygen. State to State Rate Constants," Chemical Physics Letters, Vol. 200, No. 4, 1992, pp. 382-386. doi:10.1016/0009-2614(92)87008-D

[47] Billing, G. D., "Rate Constants and Cross Sections for Vibrational Transitions in Atom-Diatom and Diatom-Diatom Collisions,' Computer Physics Communications, Vol. 32, No. 1, 1984, pp. 45-62. doi:10.1016/0010-4655(84)90007-9

[48] Millikan, R. C., and White, D. R., "Systematic of Vibrational Relaxation," Journal of Chemical Physics, Vol. 39, No. 12, 1963, pp. 3209-3213. doi:10.1063/1.1734182

[49] Ormonder, S., "Vibrational Relaxation Theories and Measurements," Reviews of Modern Physics, Vol. 47, No. 1, 1975, pp. 193-258. doi:10.1103/RevModPhys.47.193

[50] Baulch, D., Drysdale, D., and Horne, D., Evaluated Kinetic Data for High Temperature Reactions, Vols. 2-3, CRC, Boca Raton, FL, 1973.

[51] Camac, M., and Vaughan, A., "O $\mathrm{O}_{2}$ Dissociation Rates in $\mathrm{O}_{2}-\mathrm{Ar}$ Mixtures," Journal of Chemical Physics, Vol. 34, No. 2, 1961, pp. 460 470.

[52] Taylor, R. L., Camac, M., and Feinberg, R. M., "Measurements of Vibration-Vibration Coupling in Gas Mixtures," AVCO-Everett Research Lab., Rept. 250, 1966.

[53] Skews, B. W., "Aspect Ratio Effects in Wind Tunnel Studies of Shock Wave Reflection Transition," Shock Waves, Vol. 7, No. 6, 1997, pp. 373-383. doi:10.1007/s001930050092

[54] Gimelschein, S., Markelov, G., and Ivanov, M., "Relaxation and Rarefaction Effects on Shock Wave Reflections," AIAA Paper 
1998-2819, 1998.

[55] Grasso, F., and Paoli, R., "An Analytical Study of Mach Reflection in Nonequilibrium Steady Flows," Physics of Fluids, Vol. 11, No. 10 , 1999, pp. 3150-3167. doi:10.1063/1.870172

[56] Burtschell, Y., Zeitoun, D. E., and Ben-Dor, G., "Steady Shock Wave Reflections in Thermochemical Nonequilibrium Flows," Shock Waves, Vol. 11, No. 1, 2001, pp. 15-21. doi:10.1007/PL00004057

[57] Grasso, F., and Paoli, R., "Simulations of Shock-Wave Reflections in Nonequilibrium Flows," Journal of Spacecraft and Rockets, Vol. 37, No. 2, 2000, pp. 224-234. doi: $10.2514 / 2.3550$

[58] Luque, J., and Crosley, D. R., "LIFBASE: Database and Spectral Simulation Program (Version 1.5)," SRI International, Rept. MP 99009, 1999.

[59] Kovacs, I., Rotational Structure in the Spectra of Diatomic Molecules, American Elsevier, New York, 1969.

[60] Amiot, C., "The Infrared Emission Spectrum of NO: Analysis of the $\Delta v=3$ Sequence up to $v=22$," Journal of Molecular Spectroscopy, Vol. 94, No. 1, 1982, pp. 150-172. doi: $10.1016 / 0022-2852(82) 90301-0$
[61] Ory, H. A., Gittleman, A. P., and Maddox, J. P., "Franck-Condon Factors for the NO Beta and Gamma Band Systems," Astrophysical Journal, Vol. 139, No. 1, 1964, pp. 346-356.

[62] Luque, J., and Crosley, D. R., "Radiative and Predissociative rates for NO $A^{2} \Sigma^{+} v^{\prime}=0-5$ and $D^{2} \Sigma^{+} v^{\prime}=0-3, "$ Journal of Chemical Physics, Vol. 112, No. 21, 2000, pp. 9411-9416. doi:10.1063/1.481560

[63] Luque, J., and Crosley, D. R., "Transition Probabilities and Electronic Transition Moments of the $A^{2} \Sigma^{+} \rightarrow X^{2} \prod$ and $D^{2} \Sigma^{+} \rightarrow X^{2} \prod$ Systems of Nitric Oxide," Journal of Chemical Physics, Vol. 111, No. 16, 1999, pp. 7405-7415. doi:10.1063/1.480064

[64] Velasco, A. M., Martin, I., Lavin, C., and Bustos, E., "Radiative Lifetimes for the $A^{2} \Sigma^{+}\left(v^{\prime}=0-7\right)$ and $\left.D^{2} \Sigma^{+} v^{\prime}=0-5\right)$ Rydberg States of NO," Molecular Physics, Vol. 103, No. 10, 2005, pp. 1375-1385. doi:10.1080/00268970500052296

[65] McBride, B. J., and Gordon, S., "Computer Program for Calculation of Complex Chemical Equilibrium Compositions and Applications, 2: Users Manual and Program Description,” NASA CR-1311, 1996.

J. Gore Associate Editor 